\title{
Spider webs in monitoring of air pollution
}

\author{
Radosław Rutkowski ${ }^{1, *}$ Justyna Rybak $^{1}$, Tomasz Mach ${ }^{2}$, and Wioletta Rogula-Kozłowska ${ }^{3}$ \\ ${ }^{1}$ Wrocław University of Science and Technology, Department of Environmental Protection, \\ 27 Wybrzeże Wyspiańskiego St., 50-370 Wrocław, Poland \\ ${ }^{2}$ MLU-Recordum, 16 Połomińska St., 40-585 Katowice, Poland \\ ${ }^{3}$ The Main School of Fire Service, Faculty of Fire Safety Engineering, 52/54 Słowackiego St., \\ 01-629 Warsaw, Poland
}

\begin{abstract}
Biomonitoring is a significant tool of environmental protection strategies. Variety of bioindicators are used worldwide, particularly mosses, lichens and tree leaves. However, they revile many considerable disadvantages, e.g. limitation to vegetative season, moisture demand, exposition to severe weather conditions, limited time of monitoring. Classical impactors, on the other hand, are expensive, cannot be used without supervision and allow only for short-term monitoring. Spider webs, however, reveal features of extraordinary bioindicators. Webs are abundant, easy to collect, costless and can be found all year round, despite vegetative season. Spider silk is a very efficient, non-selective accumulator of contaminants, that allows for long-term monitoring. Thanks to this characteristics, spider webs proved to be immensely useful bioindicators of air pollution. They allow for monitoring of heavy metals, Polycyclic Aromatic Hydrocarbons (PAHs), dioxins, so as assessment of mutagenic activity and anthropopression assessment and indication of dominant source of pollutants. Most of the researches concerning application of spider webs as bioindicators have been conducted in Wroclaw, Poland. This paper reviews current knowledge on spider webs in monitoring of air pollution.
\end{abstract}

\section{Introduction}

Air pollution is a rising concern of modern society. In 2015, over 4 million people died all over the world because of the exposure to atmosphere pollutants. According to Institute for Health Metrics and Evaluation (IHME), the main causes of these deaths were: chronic obstructive pulmonary disease $(27.1 \%)$, lower respiratory infections $(24.7 \%)$, ischemic heart disease $(17.1 \%)$, lung cancer $(16.5 \%)$ and stroke (14.2\%) [1]. Sources of these threats are mostly industrial, which include: power generation, road transport, waste disposal and variety of domestic sources. Agriculture, along with burning of agricultural waste, is also a source of pollution, which must not be overlooked.

Consistent development of industries, urbanization and transport demand efficient, cheap and universal tools for monitoring their impact on the environment. For this purpose, new

\footnotetext{
*Corresponding author: radoslaw.rutkowski@pwr.edu.pl
} 
methods of biomonitoring are being developed and refined, among which, spiders usage steps out of the line.

Biological monitoring term was defined in 1980 Luxemburg seminar, organized by the European Economic Community (EEC), National Institute for Occupational Safety and Health (NIOSH) and Occupational Safety and Health Association (OSHA). The aim of the seminar was to examine the roles of ambient and biological monitoring in protecting the health of workers exposed to toxic agents and to define a multidisciplinary approach to this monitoring. The biological monitoring was defined as the measurement and assessment of workplace agents or their metabolites either in tissues, secreta, excreta, expired air on any combination of these to evaluate exposure and health risk compared to an appropriate reference [2]. In most common comprehension, biological monitoring is the usage of the living organisms to estimate and track changes in the environment.

Biomonitoring is typically employed either as a complementary method or as an alternative method for accurate large-scale studies when the extensive use of equipment onsite is expensive or impractical. The advantage of this methods is that they can substantiate the physical and chemical data by physiological data referring to the viability of this material. A wide variety of species are known as useful bioindicators in aquatic and terrestrial ecosystems. Depending on the type of organisms used for monitoring, they are classified into plants (e.g. mosses, lichens, tree leafs, algae), animals and microorganisms.

Many of them revile considerable disadvantages. For example: lichens, which are considered to be a textbook bioindicators might be rare in urban areas due to their vulnerability to $\mathrm{SO}_{2}$, sulphur and nitrogen based pollutants, which confounds their bioaccumulative properties. Content of lichens and mosses depends on surface they grow, hence finding specimens in different areas with similar composition might be hindered. These organisms are very moisture-dependent, so utilized "bags" must be precisely prepared in order to preserve drying process [3]. Because of the moisture issue, short term exposition might be recommended.

Spiders are the largest order of arachnids that lately have proved to be extraordinary bioindicators - vastly thanks to a spider silk - a unique device in Animalia kingdom, which guaranteed them evolutionary success.

Spiders inhabit almost any kind of environment and dwell readily in urbanized areas, which makes their silk a greatly available sampling material. Many spider species reside households and are well tolerated by humans (e.g. Pholcidae family). Spiders web are thus vastly accessible, easy to collect and costless. There are independent of vegetative season factors like sunlight or temperature. Webs are protected from severe weather conditions like rain or wind, hence the accumulation rates depends on the site location. Sample collection is non-invasive and does not require killing animal itself $[4,5,6]$.

Webs efficiently accumulate toxins, which enables a long-term monitoring of air pollution level in contrast to standard measurements, which allow only for short-term studies. What is more, passive samplers use mostly selective sorbents, which cannot be applied for wide range of air pollutants.

\section{Heavy metals}

Heavy metals are non-biodegradable compounds which can bind to ecosystem's trophic chain, many of them exhibit toxic and carcinogenic properties. There are many anthropogenic sources of heavy metals emission to the atmosphere, among which vehicular traffic rises increasing concern. Metals which pose particular threat for the environment are: chromium $(\mathrm{Cr})$, lead $(\mathrm{Pb})$, mercury $(\mathrm{Hg})$, cadmium $(\mathrm{Cd})$, arsenic $(\mathrm{As})$, copper $(\mathrm{Cu})$, manganese $(\mathrm{Mn})$, nickel (Ni), zinc ( $\mathrm{Zn})$ and silver $(\mathrm{Ag})$. 
Hose at al. investigated application of spider webs in biological monitoring at the beginning of XXI century [4]. Research proved usefulness of this material as bioaccumulative environmental indicators. Analysis of spider webs sampled from limestone arches in New South Wales (Australia) displayed several times higher levels of $\mathrm{Pb}$ and $\mathrm{Zn}$ at Jenolan Caves compared to reference sites at Abercrombie and Wombeyan Caves. The high concentrations at Jenolan was explained by vehicular traffic emissions that travelled through the arch [4].

Xiao-li et al. [5] tested practicality of spider webs for detecting motor vehicle emission in urban area in China. Webs from two common spiders (Achaearanea tepidariorum and Araneus ventricosus) were tested for concentration of $\mathrm{Pb}, \mathrm{Zn}, \mathrm{Cu}$ and $\mathrm{Cd}$ and data was compared to the proximity and volume of motor vehicle traffic at the sites. Beside significant differences in heavy metal concentrations between polluted and references sites, the study showed also distance-, and like Hose at al. [4], age-related differentials.

Since Xiao-li et al. [5], research on spider webs have been conducted in Poland by Rybak at al. and focused mainly on road traffic emissions [7-11]. Rybak investigated cumulative ability of spider webs to heavy metals across Wrocław, Lower Silesia. First preliminary study incorporated two species of Agelenidae family (Malthonica silvestris and Malthonica ferruginea) [6].

Agelenids, known as funnel weavers, build non-sticky, dense, horizontal webs with a funnel retreat on, or above the ground. Spiders from this family do not eat their webs. They are commonly found in urbanized areas like road tunnels, bridges, parking lots and homesteads. Webs of Agelenidae, Pholcidae and Linyphiidae family proved to be excellent bioindicators of atmospheric pollutants [7-11].

Study displayed significant differences between samples collected at investigated sites in case of $\mathrm{Pb}, \mathrm{Zn}$ and $\mathrm{Pt}$ concentrations, indicating their potential usefulness as bioindicators [6]. Study conducted by Rybak in 2015 on several elements revealed varying concentrations of all elements at sites, with a following general descending order of concentration: $\mathrm{Fe}>\mathrm{K}>\mathrm{Al}>\mathrm{Zn}>\mathrm{Mg}>\mathrm{Ti}>\mathrm{Mn}>\mathrm{Cu}>\mathrm{Pb}>\mathrm{Ni}>\mathrm{Cr}>\mathrm{V}>\mathrm{Co}>\mathrm{Pt}>\mathrm{W} \quad[10]$. Principal component analysis (PCA) of data done on Malthonica silvestris webs revealed two contamination sources: road traffic emissions and industrial.

Rybak et al. also evaluated whether data obtained from webs reflect the level of air pollution measured with conventional methods [11]. The airborne particulate matter (PM) and associated heavy metals $(\mathrm{Pb}, \mathrm{Zn})$ collected in Wrocław were analysed with the use of classic method of air pollution assessment (impactors) and with webs of Malthonica silvestris. Study revealed correlation between average heavy metals concentrations on spider webs and average concentrations of $\mathrm{Pb}$ and $\mathrm{Zn}$ bound to submicron particles (PM1). Results conclude that content of heavy metals found on spider silk may not match the composition of corresponding elements present in bioaerosol. Overall, study confirmed usefulness of spider webs in monitoring of traffic emission as they are able to capture PM in a manner similar to flora-based bioindicators that have been used up to date, but spider silk have additional advantages like long time of exposition

\section{Polycyclic Aromatic Hydrocarbons}

Polycyclic Aromatic Hydrocarbons (PAHs) and their derivatives are formed mostly during incomplete combustion or pyrolysis of organic material [12]. Diesel engines are one of the main sources of this organic particles. PAHs pose substantial threat to humans due to their mutagenic and carcinogenic properties. Rybak and Olejniczak for the first time investigated possible use of spider webs as indicators of polycyclic aromatic hydrocarbons (PAHs) pollution [9].

Results from Wroclaw displayed a significantly higher mean concentrations of PAHs in samples collected at a heavy traffic sites compared to samples from reference/background 
sites. Data indicated a positive correlation between PAHs content and close vicinity to the roads, confirming the contribution of pollution emissions from vehicular traffic. Agelenidae webs proved to be efficient indicators of PAHs. Interesting finding was, that in case of outdoor air, spider webs are more suitable for detecting PAHs of high molecular mass, rather than low molecular mass due to direct deposition of this compounds [9].

\section{Dioxins}

Dioxins compounds are persistent environmental pollutants, which can accumulate in the food chain, mainly in the fatty tissue of animals. They are mainly by-products of industrial processes and combustion of industrial compounds including improper municipal waste incineration and burning of trash. They are known for mutagenic and carcinogenic properties.

Spider silk displays suitable properties to determine the environmental exposure to polichlorinated dibenzo-para-dioxins (PCDDs). Preliminary study of Rybak et al. [13] showed that samples of spider webs collected in Lower Silesia adsorbed dioxins from air. Concentration of PCDDs was dependent on proximity to medical solid waste incinerator, major roadways and on municipal waste/garbage burning at backyards and in stoves. Spider webs displayed characteristics of fine PCDDs indicator and revealed exposure of inhabitants to this highly toxic pollutants.

\section{Mutagenic activity}

In order to assess environmental threats of air pollution, complex chemical analysis of air samples might not be efficient enough due to complex composition of the mixture and cholinergic interactions between individual compounds [14]. For obtaining reliable information about biological activity of pollutants, bacterial test for mutagenicity, e.g. the one proposed by Ames [15] are now commonly used. Studies by Rybak at al. and Rutkowski at al. $[16,17]$ proved successful application of spider webs in Ames mutagenicity assessment of both indoor and outdoor air pollution. Spiders dwell readily in human buildings, where adults of Pholcidae and Agelenidae family can be observed for whole year. As they naturally occur at homes or in outdoor localities such us road tunnels we can use them for cheap, long term monitoring of air pollutants, what is particularly utile in case of indoor monitoring. Study of Rybak at al. [16] has shown mutagenic activity of web samples collected from rooms exposed to pyrogenic and petrogenic emission (boiler room, garage, bedroom in a house nearby traffic road). Houses at sites without this potential threats did not display mutagenic activity.

\section{Mineralogical composition}

Application of spider webs in identification of various inorganic particles by SEM-EDX (Scanning Electron Microscope with Energy Dispersive X-Ray Analyser) technique was studied by Górka at al. [18]. This technique allows chemical and morphological characteristics of geological and trace elements particles identified on webs surface. Spider silk revealed its potential to be a tool for anthropopression assessment and indication of dominant source of pollutants. The extent of adsorbed particles on webs, so as their size and mineralogical composition varied largely depending on spider taxa and exposure time. Identified inorganic particles were mostly a derivatives of soil deflation or buildings/monuments weathering. Analysis of blank laboratory spider webs indicated that this material transported to real environment may serve as passive sampler both for mineralogical characteristics of atmospheric dust, as well as their chemical and isotopic 
signature. Webs of Pholcidae family were recommended for this kind of studies in comparison to Agelenidae family, as the former resembled better particle accumulation property.

\section{Magnetic susceptibility}

Magnetic susceptibility is an interesting method of environmental pollution study in which spider webs also found application since they are diamagnetic. Exposure of pollutants containing metallic particles on spider silk increases value of its magnetic susceptibility, thus variation of this property should reflect the level of ambient air pollution. Rachwat et al. [19] applied this method for monitoring of both outdoor and indoor dust samples. Samples collected in rural and urban areas in Poland displayed significant increase in magnetic susceptibility compared to clean laboratory spider webs. It indicated serious contamination of PM containing ferromagnetic particles, presumably of anthropogenic source. Based on that, biomagnetic investigation of spider webs may be recommended as a method for monitoring of airborne pollution.

\section{Disscusion}

Ubiquity of major pollutants, mainly heavy metals, PAHs and dioxins in environment, despite venue of their identification (environmental component, e.g. air, water, soil, sludge) depends mostly on scale of their emission. In different areas, distinct emission sources determine scale of pollution in qualitative and quantitative sense. Each technological emission origin, e.g. exhaustion pipes, power plant chimneys, or brazier batteries have its own chemical profiles, hence proportions of pollutants types of that source are generally determined. This knowledge is used worldwide for: associating pollutants in a given area with specific sources, which ultimately allows for; identification of priority pollution sources and environmental issues of this area; evaluating environmental threats on this area, especially for the local living organisms; taking rational actions leading to elimination of threats associated with emission of pollutants to the environment [20].

Physical and chemical forms of which various pollutants enter environment, especially the air, determine their onward migration in this environment, so as manner and range of contamination by other components [21]. It is necessary to develop methods of monitoring, which allow for accurate, extensive and common monitoring at the same time. Principally, this applies to air, from which pollutants migrate to remaining components. Classical methods are restricted to many limitations. Apart from mainly technical ones, like costs, localization characteristics and selectivity, that limit their universality, there are methodical limitations, as well. In example, in monitoring of air pollution by PAHs, dioxins and heavy metals, it is necessary to extract PM from air first and afterwards, to determine its components $[22,23]$. There are some principle problems related to this methodology. First of all, only PM contaminants are assumed, thus only solid and liquid formed. It is commonly known that some metals and definitely most of PAHs, exist in air in gaseous and semi-gaseous forms [24]. What is more, depending on PM components, which are being analysed, variety of filters and collecting materials are used. They are determined by chemical composition of filtering material, therefore by content of substances in so called black samples, so as by analytical methods limitations used in laboratories [25].

What is more, application of only one filtering material usually implies indication of only one group of compounds. To detect many compounds simultaneously, it is necessarily to use several PM samplers containing several types of filters [26]. Another issue is application of different samplers types indoor and outdoor due to technicalities [27, 28]. Despite the 
necessity of appliance of both types of devices for this kind of monitoring, there is also the limitation due to impossibility of direct comparison of indoor and outdoor pollutants as different methods of measurement are applied.

There are more similar problem and restrictions related to classical methods of measurements of PM and other pollutants. The limitation scarcely mentioned before, but presumably most important, is the expense issue, which induces applying of conventional methods only in prechosen, neuralgic locations, or if it serves scientific researches, it is only temporal and short-term. It seems that yet mentioned, along with other issues related to contaminants identification may be overcome by application of medium in a form of spider webs. Nevertheless, before common praxis of spider webs, precise systematization of their application is necessary, along with design and acceptance of uniformed units in description of contamination. Sampling of heavy metals, PAHs or dioxins by spider webs is too distinct in comparison to street/urban dust, wet and dry deposition or other biological samplers (e.g. mosses and lichens), which are now widely used. Nonetheless, similarly to spider webs, information gathered by those methods are difficult to compare and to relate to concentrations of pollutants in air. Therefore, it is necessary to investigate the relationship between data collected by spider webs and quality of air in research field. Simultaneous measurements of contaminants assembled on spider webs and/or passive sampler must be performed. The key parameter in this kind of research would be the determination of optimal time of monitoring.

There are also other aspects that need further investigations. One of the most challenging facets of spider webs utilization is the mechanism of accumulation of pollutants.

Hose et al. [4] analyzing non-sticky cribellate spiders webs (Badumna socialis and Stiphidion facetum) demonstrated that washing webs with diluted acid reduced heavy metal concentrations up to $80 \%$ and concluded that contaminants do not incorporate into web matrix but bind to web surface. Nevertheless, webs of different families may display distinct efficiency in trapping contaminants.

Spiders tolerate high concentration of metals in environment and their bodies are efficient accumulators of this elements, so the content of metals in their bodies may reflect the metal amount in the environment [29]. For sake of reliable air monitoring, it is essential to distinguish external deposition of contaminants from incorporation of chemical particles passed from spiders hemolymph via spinnerets. Study of Rybak at al. [30] (paper under review) on Eratigena atrica fed with food contaminated by $\mathrm{Cu}$ and $\mathrm{Pb}$ proved the correlation between levels of $\mathrm{Cu}$ and $\mathrm{Pb}$ in webs and spiders. Research displayed that washing webs with shampoo and organic solvents decreased the concentration of heavy metals nearly by $70 \%$, which is in accordance with Hose et al. [4] and suggests the dominance of external pathway of pollution (presumably by excreta or remains of the consumed prey). Remaining contamination must have been caused by internal incorporation.

Next step in research of application of spider webs in biomonitoring, that seems to be very interesting would be comparison of levels of PAHs displayed on spider webs and in body of spiders.

The concern that is frequently expressed in case of research on spider webs is the estimation of time of exposition to pollutants. In fact, it is easy to date the time of the web exposition by removing the old web and using only a new construction or to apply transferred webs derived from the laboratory $[7,18]$.

\section{Conclusions}

Spider webs reflect many features of perfect bioindicator. They are abundant, cheap, easy to collect and identify. Webs are usually woven in secluded places preventing them from destroying by weather conditions. Cumulative ability of spider webs as a consequence of their chemical structure, and independence from vegetation period, allow for unique 
opportunity of assessment of air pollution level in a long-term period, contrary to the classic measurements. Classic samplers are also expensive and need continuous supervision. Spider silk is a non-selective and highly efficient natural passive sampler material, thus it can be used for monitoring of vast range of air pollutants, like heavy metals, PAHs, dioxins.

The investigations were co-financed within the framework of the order No. 0401/0004/17 with the specific subsidy granted for the Faculty of Environmental Engineering Wroclaw University of Science and Technology (W-7) by the Minister of Science and Higher Education

\section{References}

1. Health Effects Institute. 2017. State of Global Air 2017. Data source: Global Burden of Disease Study 2015. IHME (2016)

2. A. Berlin, R.E. Yodaiken, D.C Logan, Int Arch Occup Environ Health 50 (1982)

3. H.G Zechmeiste, S. Dullinger, D. Hohenwallner, A.Riss, A. Hanus-Illnar, S. Sharf, Environ. Sci. Pollut. Res. 13 (2006)

4. G.C. Hose, J.M. James, M.R. Gray. Environ Pollut, 120, 725-733 (2002)

5. S. Xiao-Li, P. Yu, G.C. Hose, C. Jian, L, Feng-Xiang, Bul Environ Contam Toxicol, 76, 271-277 (2006)

6. J. Rybak, OCHR SR. 34, 47-50 (2012)

7. J. Rybak, I. Sówka, A. Zwoździak, Environ. Prot. Eng. 38, 175 (2012)

8. J. Rybak, Ecol. Eng. 15, 39 (2014)

9. J. Rybak, T. Olejniczak, Environ. Sci. Pollut. Res. 21, 2313 (2014)

10. J. Rybak, Water. Air. Soil Pollut. 224 (2015)

11. J. Rybak, I. Sówka, A. Zwoździak, M. Fortuna, K. Trzepla-Nabagło, Ecol. Chem. Eng. S, 22, 389 (2015).

12. K. Widziewicz, W. Rogula- Kozłowska, G. Majewski, Int. J. Environ Res. 11 (2017)

13. J. Rybak, R. Rutkowski, E3S WEB CONF, 28 (2018)

14. L.D. Claxton, P.P. Matthews, S.H. Warren, Mutat. Res. 567, 347 (2004)

15. B.N. Ames, J. McCann, E. Yamasaki, Mutat. Res., 31, 347 (1975)

16. J. Rybak, R. Rutkowski, K. Piekarska, M. Bełcik, W: 2nd Symposium "Air Quality and Health", book of abstracts, 79-79 (2017)

17. R. Rutkowski, P. Jadczyk, J. Rybak, E3S WEB CONF, 44 (2018)

18. M. Górka, W. Bartz, J. Rybak, J AEROSOL SCI, 123, 63-75 (2018)

19. M. Rachwał, J. Rybak, W. Rogula- Kozłowska, Environ. Pollut., 234, 543-551 (2018)

20. J.H. Seinfeld, S.N. Pandis, Atmospheric chemistry and physics: from air pollution to climate change, John Wiley \& Sons (2012)

21. E. Sarti, L. Pasti, M. Rossi, M. Ascanelli, A. Pagnoni, M. Trombini, M. Remelli, Environ Sci Pollut Res, 6(4), 708-71 (2015)

22. J.C. Chow, J. Air Waste Manage. Assoc., 45, 320-382 (1995)

23. B. Brunekreef, R.L. Maynard, Atmos Environ, 42(26), 6425-6430 (2018)

24. A. Dvorská, G. Lammel, J. Atmos. Environ., 45(2), 420-427 (2011)

25. C.S. Davis, P. Fellin, R. Otson, JAPCA, 37(12), 1397-1408 (1987)

26. W. Rogula-Kozłowska, K. Widziewicz, G. Majewski, Microchemical J, 132, 327-332 (2017) 
27. L. Morawska, Control of Particles Indoors - State of the Art. Proceedings of Healthy Buildings 2000, 2, 9-20, Espoo, Finland (2000)

28. L. Morawska, T. Salthammer, Indoor environment: airborne particles and settled dust, Wiley-VCH (2013)

29. M.P. Jung, J.H. Lee, Environ. Monit. Assess. 184, 1773-1779 (2012)

30. J. Rybak, B.E. Hanus-Lorenz, W. Rogula-Kozłowska, K. Loska, K. Widziewicz, R. Rutkowski, W: International Conference on Advances in Energy Systems and Environmental Engineering (ASEE17), book of abstracts / ed. by Bartosz Kaźmierczak. Wrocław : Oficyna Wydawnicza Politechniki Wrocławskiej, 121-122 (2017) 